198 Revista Ius et Praxis - año 14 - n 1

El sistema de recursos procesales en el ámbito civil

en un Estado democrático deliberativo

Raúl Núñez Ojeda

páginas 199-223

\title{
EL SISTEMA DE RECURSOS PROCESALES EN EL ÁMBITO CIVIL EN UN ESTADO DEMOCRÁTICO DELIBERATIVO*
}

\author{
Raúl Núñez Ojeda"
}

RESUMEN El artículo aborda el cambio de paradigma que representa el establecimiento del recurso de nulidad, como único medio de impugnación en contra de las sentencias definitivas, que se pretende implementar en la proyectada reforma del sistema procesal civil chileno. Para alcanzar ha comprender las diversas aristas del problema se tematiza la función que desarrollan los jueces en el procedimiento de adjudicación en un Estado de Derecho, como las limitaciones que se presentan en atención a los criterios de organización de la tutela procesal que inspiran la reforma y la adopción del sistema de libre valoración de la prueba (o sana crítica).

\section{PALABRAS CLAVES}

Derecho procesal civil, sistema de recursos, reforma del proceso civil, recurso de nulidad civil

\begin{abstract}
The article approaches the change of paradigm that represents the establishment of the nullity recourse as the only mean of impugnation against final judgments, as it is intended to be in the projected reform of the Chilean civil procedural system. To

Este artículo tiene su origen en un trabajo presentado el día 24 de agosto del 2007 en la Universidad de Talca, en el marco de las "Primeras Jornadas Interdisciplinarias de Derecho", cuyo título fue "Los principios generales del Derecho". El texto que hoy se publica es una versión revisada, corregida y aumentada del mismo. Agradecemos al Profesor Dr. Diego Palomo Vélez por la invitación y por las sugerentes discusiones que se sucedieron sobre el tema. Trabajo decepcionado el 2 de abril de 2008, y aprobada su publicación el 20 de mayo de 2008.. Doctor en Derecho, Profesor de Derecho Procesal, Universidad de Chile. Profesor invitado en la Universitat Pompeu Fabra (España). Correo electrónico: raununez@derecho.uchile.cl.

Revista Ius et Praxis - año 14 - n 1199

Raúl Núñez Ojeda

understand the several edges of the problem, the author analyze the function that judges develops in the procedure of awarding in a context of Rule of Law, as well as the limitations that are presented in consideration of the organization criteria of the procedural protection that inspire the reform, and the adoption of the system of free appraisal of the evidence (or healthy criticism).
\end{abstract}

\section{KEYWORDS}

Civil Procedural Law, system of recourses, civil procedure reform, recourse of civil nullity

\section{1.- Introducción}

El tópico del presente artículo es analizar el sistema de recursos procesales civiles que reconoce el nuevo enjuiciamiento civil contenido en el anteproyecto de Código Procesal Civil ${ }^{1}$. El citado anteproyecto fue el resultado de un trabajo de un conjunto de profesores de diversas Universidades de la ciudad de Santiago en el cual me correspondió trabajar junto con otros académicos del Departamento de Derecho Procesal de la Facultad de Derecho de la Universidad de Chile ${ }^{2}$. Por la importancia de la materia que fue objeto de la nueva regulación me gustaría hacer previamente ciertas aclaraciones y precisiones que permitirán entender mejor el contexto del cambio de perspectiva en el sistema recursivo. 
Un tema de gran sensibilidad para el usuario de la administración de justicia es, precisamente, el grado de control que un sistema procesal reconoce de las resoluciones que dictan los funcionarios que integran los órganos que ejercen la función de adjudicación en un Estado de Derecho ${ }^{3}$. En otras palabras, para la sociedad en su conjunto resulta importante saber hasta que punto se puede controlar el ámbito de discrecionalidad del órgano que ejerce la jurisdicción al decidir un caso determinado ${ }^{4}$. Ciertamente, que hablo de discrecionalidad,

El texto del anteproyecto de nuevo Código Procesal Civil se puede consultar en: Revista de Estudios de la Justicia, Número 8, 2006, págs. 47 y ss.

Para una visión panorámica de la historia del proyecto de nuevo Código Procesal civil, ver por todos: Núñez Ojeda, Raúl, "Hacia un nuevo proceso civil en Chile. Un estudio sobre el movimiento de reforma de la justicia civil al sur del mundo", Revista Actualidad Jurídica, número 17, Universidad del Desarrollo, Santiago, 2008 , págs. 31 a 33.

También hemos dejado de lado la discusión sobre una teoría general de los medios de impugnación. Con todo, una buena aproximación al tema se puede ver en: Tavolari Oliveros, Raúl, "Hacia una teoría general de la impugnación", Comentarios procesales, Edeval, Valparaíso, págs. 37 y ss.

Para una visión de las reformas de los poderes judiciales de la europa continental e insular confrontar con: Bell, John, Judiciaries within Europe. A Comparative Review, CUP, Cambridge, 2006, especialmente págs. I a 43.

200 Revista Ius et Praxis - año $14-\mathrm{n}^{\circ} 1$

El sistema de recursos procesales en el ámbito civil en un Estado democrático deliberativo

ya que en las hipótesis de arbitrariedad no se podría hablar en sentido estricto de decisión jurisdiccional, por ser un acto de puro voluntarismo del sujeto que actúa en nombre del Estado adjudicador. ${ }^{5}$

Por otro lado, el tema entra de lleno en una discusión mucho más amplia que supera el marco del fenómeno jurídico, me refiero al tópico de la falibilidad humana. Efectivamente, según la doctrina clásica nacional, los recursos han sido creados por el Legislador como medio de corregir los errores, vicios, agravios o faltas en que incurran los jueces, ya que, como todas las personas, no son infalibles y como personas que son los jueces, ellos también pueden equivocarse. ${ }^{6}$

Sin desconocer que la doctrina clásica tiene en parte razón, nuestro enfoque será un tanto diverso. Para nosotros el punto de partida es la noción de Estado democrático deliberativo estructurado por el filósofo alemán Jürgen Habermas ${ }^{7}$. Así las cosas, debemos preguntarnos ¿Cuál es la función que realizan los jueces al resolver un caso dentro de un Estado democrático deliberativo? Sólo de esta manera podremos saber que controlar y que parte queda fuera de esta actividad.

\section{2.- El discurso que desarrollan los órganos jurisdiccionales}

Para nosotros la respuesta se construye a partir de la diferencia entre discurso de fundamentación (o justificación) y discurso de aplicación o adecuación, como formas discursivas complementarias ${ }^{8}$. El primero tiene por objeto justificar la validez o corrección de una norma,

Aquí nos encontramos con los supuestos de responsabilidad del juez. Sobre el tema consultar en español, entre otros: Montero Aroca, Juan, Independencia y responsabilidad
del juez, Civitas, Madrid, 1990, págs. 182 y ss.; Díez-Picazo Giménez, Ignacio, Poder Judicial y responsabilidad. La Ley, Madrid, 1993, págs. 20 y ss.; y, Delgado del Rincón, Luis Esteban, Constitución, Poder Judicial y responsabilidad, Centro de Estudios Constitucionales, Madrid, 2002, págs. 23 y ss.

Ver entre otros: Benavente Gorroño, Darío, Derecho procesal civil, Editorial Jurídica de Chile, Santiago, 2002, pág. 147; y, Casarino Viterbo, Mario, Manual de Derecho procesal (Derecho Procesal Civil), tomo IV, Editorial Jurídica de Chile, Santiago, 2007, pág. 129.

Habermas, Jürgen, Faktizitat und Geltung, Suhrkamp Verlag, Frankfurt, 1992, págs. 349 y ss. Sobre la posición de Habermas desde una pespectiva crítica: Grimm, Dieter, "Bedingungen demokratischer Rechtsetzung", Die Offentlichkeit der Vernunft der Offentlichkeit. Festschrift für Jürgen Habermas (L. Wingert / K. Günther), Suhrkamp Verlag, Frankfurt, 2001, págs. 489 y ss.

Aquí seguimos el pensamiento estructurado por Habermas y su discípulo Günther (Günther, Klaus, Der Sinn für Angemessenheit. Anwendungsdiskurse in Moral und Recht, Suhrkamp Verlag, Frankfurt, 1988, passim, y, Habermas, Jürgen, Faktizitat und Geltung, op. cit, págs. 238 y ss.). Con todo, existe una opinión diversa del Profesor Alexy (Alexy, Robert, Teoría de la argumentación jurídica, Centro de Estudios Constitucionales, Ma-

Revista Ius et Praxis - año $14-n^{\circ} 1201$

\section{Raúl Núñez Ojeda}

justificación que viene dada por el principio de universalidad. Aun cuando atendiendo al discurso de justificación o fundamentacion una norma sea válida ello no significa que esa norma deba ser automáticamente aplicada al caso concreto. Es aquí donde entra enjuego el discurso de aplicación o adecuación: este discurso se refiere a la corrección de la decisión jurídica, en la cual hay que establecer si la norma prima facie aplicable es adecuada a una situación determinada, para lo que es necesario tener en cuenta todos los datos que caracterizan a esa situación, es decir, la situación de aplicación. La diferencia entre discurso de fundamentacion y discurso de aplicación de las normas jurídicas reside en que el primero es un discurso práctico sobre la validez de las normas independientemente de la situación 
individual en la que serán aplicadas; mientras que el discurso de aplicación está centrado en la adecuación de las normas a las circunstancias relevantes del caso concreto (aspectos o circunstancias de hecho) ${ }^{9}$. Por tanto, fundamentacion y aplicación son dos formas discursivas complementarias, la primera es labor del Poder Legislativo y la segunda es propiamente el discurso del órgano jurisdiccional.

También, se debe considerar que la decisión judicial debe ser una decisión doblemente limitada ${ }^{10}$. Por un lado, por elprincipio de legalidad, que implica que el juez tiene que tomar la decisión aplicando el ordenamiento jurídico; en otras palabras, la decisión judicial tiene que ser una decisión legal. Por otro lado, como el ordenamiento no predetermina totalmente la solución a los casos individuales, hay un segundo límite a la decisión judicial, límite que viene dado por la correcta justificación de la misma, justificación que está en función de las razones dadas a favor de cada una de las opciones que se le plantean al juez en el proceso de aplicación. Por lo tanto, lo decisivo en la aplicación judicial del derecho no es sólo la aplicación de enunciados jurídicos (de fuentes del derecho) como fundamentos o razones para la decisión, sino también las razones dadas a favor de la aplicación de dichos enunciados frente a otros potencialmente aplicables, la determinación de un preciso significado de los mismos frente a otras interpretaciones, la consideración de determinados hechos como probados (alternativamente a las razones a favor de los mismos como no probados) y como encuadrables en una categoría jurídica (y no en otra), así como la elección de una correcta consecuencia jurídica dentro de las alternativas legales. ${ }^{11}$

drid, 1997, passim) que hacer referencia a la tesis del "caso especial". El citado autor sostiene que la pretensión de corrección también se plantea en el discurso jurídico; pero esta pretensión, a diferencia de los que ocurre en el discurso práctico general, no se refiere a que las proposiciones jurídicas en cuestión sean sin más racionales, sino sólo a que en el marco del ordenamiento jurídico vigente puedan ser racionalmente fundamentadas.

Günther, Klaus, Der Sinn fur Angemessenheit. Anwendungsdiskurse in Moral und Recht, op. cit, passim; y, Habermas, Jürgen, Faktizitat und Geltung, op. cit., págs. 272 y ss.

Sobre el problema de la interpretación me remito al escrito del discípulo del profesor K. Günther: Bung, Jochen, Subsumtion und Interpretation, Nomos, BadenBaden, 2003, passim.

Günther, Klaus, "Un concepto normativo de coherencia para una teoría de la argumentación jurídica", Doxa, Alicante, 1995, págs. 274 y ss.

202 Revista Ius et Praxis - año $14-n^{\circ} 1$

El sistema de recursos procesales en el ámbito civil en un Estado democrático deliberativo

De aquí surge asimismo la obligación de motivar las sentencias, obligación que no es sólo una exigencia de orden legal, sino que se deriva de la idea misma de la jurisdicción y de su ejercicio en los Estados democráticos, donde no pueden desligarse las ideas de jurisdicción y motivación: ésta es constitutiva de aquélla, de tal forma que la motivación no es algo obligatorio desde un punto de vista externo o formal, sino que es inherente a la aplicación de derecho. ${ }^{12}$

En otras palabras, la fundamentación se compone en el hecho de juzgar y los motivos de la decisión. Aquí junto con los considerandos jurídicos se produce la valoración de la prueba. Las disposiciones relativas a procedimientos no norman, pues, ni las razones que deban considerarse admisibles, ni tampoco la marcha de la argumentación; pero aseguran ámbitos para discursos jurídicos, que sólo en su resultado se convierte en objeto del procedimiento. Pues el resultado puede ser vuelto a examinar por las sucesivas etapas superiores. ${ }^{n}$

Esta autorreflexión institucionalizada del derecho sirve a la protección del sistema jurídico desde un doble punto de vista que representa la justicia en el caso particular y la unilateralidad en la aplicación del derecho y en el desarrollo del mismo ${ }^{14}$. Así las cosas, la finalidad del recurso consiste, primariamente, en obtener en interés de las partes decisiones correctas y, por tanto, justas, mediante la revisión de las sentencias dictadas. Con todo, la finalidad de los recursos no se agota en ello. Antes hay también un interés general por un eficaz sistema de recursos. La prohibición de la autotutela sólo se puede realizar eficazmente si las partes reciben ciertas garantías de obtener una decisión correcta. Además la secuencia de distintas etapas revisoras permite la concentración en un grupo de tribunales superiores, para terminar en el tribunal de mayor jerarquía dentro del sistema procesal (en Chile la Corte Suprema), que conduce a la unilateralidad del derecho a la vez que ha su desarrollo, ambas cosas necesarias para el sistema jurídico. Es importante tener presente que el interés público es más fuerte en

\footnotetext{
En el mismo sentido: Taruffo, Michele, La motivazione della sentenza civile, Cedam, Padova, 1975, passim. Sobre la fundamentación de las sentencias en español, ver entre otros: Iacoviello, Francesco, La motivazione della sentenza peale e il suo contrallo in cassazione, Giuffre, Milano, 1997, passim; Colomer Hernández, Ignacio, La motivación de las sentencias: Sus exigencias constitucionales y legales, Tirant lo Blanch, Valencia, 2003, págs. 157 y ss.; Igartua Salaverria, Juan, La motivación de las sentencias, imperativo constitucional, Centro de Estudios Políticos y Constitucionales, Madrid, 2003, passim; Iturralde Sesma, Victoria, Aplicación del Derecho y justificación de la decisión judicial, Tirant lo Blanch, Valencia, 2003, págs. 251 y ss.; Rodríguez Boente, Sonia Esperanza, La justificación de las decisiones judiciales, Universidad de Santiago de Compostela, 2003, págs. 199 y ss.; y, De Asís Roig, Rafael, EIJuezy la motivación en el Derecho, Dykinson, Madrid, 2005, págs. 77 y ss. En Chile tiene una opinión similar: Maturana Miquel, Cristian, "El sistema probatorio. Motivación de las sentencias y fundamento de la impugnación", Revista de Derecho Procesal, № 21, Universidad de Chile, Santiago, 2008, págs. 173 y ss. Habermas, Jürgen, Faktizitat und Geltung, op. cit, págs. 289 a 291
} 
Raúl Núñez Ojeda

el recurso de Casación que en el recurso de apelación. El interés público por la unilateralidad del derecho marca un importante rasgo de la lógica de la administración de justicia: El tribunal debe en cada caso particular proteger la coherencia del ordenamiento jurídico en su conjunto ${ }^{15}$. Sobre este aspecto volveremos más adelante.

\section{3.- Limitaciones del proceso en atención a la prueba}

Llegados a este punto conviene, además, reconocer que por razones de seguridad jurídica ${ }^{16}$ los procesos civiles tiene que terminar dentro de un plazo razonable ${ }^{17}$. Pero alguno de los lectores podría cuestionar esta limitación destacando que una de las finalidades del proceso es la búsqueda de la verdad. Así las cosas, parece apropiado hacer una breve aproximación al concepto y función de la prueba civil.

La prueba constituye uno de los capítulos más importantes del Derecho Procesal Civil. En este sentido, concordamos plenamente con Bentham ${ }^{18}$ quien señaló, ya hace mucho tiempo, que "el arte del proceso es el arte de la prueba". Con todo, es una materia que no ha tenido un desarrollo dogmático acorde con la importancia práctica que representa.

Efectivamente, los teóricos del Derecho se han preocupado más por la justificación de las decisiones judiciales, dando por descontado el problema de la selección de las premisas, o bien estudiando principalmente las decisiones interpretativas y el razonamiento judicial. ${ }^{19}$

Por otro lado, para el procesalismo tradicional, el centro de su atención se estableció en la exegesis de los textos legales que regulaban el período probatorio y, en algunas ocasiones, en el estudio de cada uno de los medios de prueba en particular. $^{20}$

Habermas, Jürgen, Faktizitat und Geltung, op. cit, pág. 290.

Sobre el tema consultar el agudo artículo de: Atria Lemaitre, Fernando, "Seguridad jurídica y Derechos Fundamentales: Sobre predictibilidad y autogobierno", Justicia Constitucional y Derechos Fundamentales, Lexis-Nexis, Santaigo, 2006, págs. 7 y ss.

Sobre el tema de la eficacia temporal del proceso ver por todos: Riba Trepat, Cristina, La eficacia temporal del proceso. El juicio sin dilaciones indebidas, JM. Bosch, Barcelona, 1997, passim.

Benthan, Jeremías, Tratado sobre las pruebas judiciales, EJEA, Buenos Aires, págs. 12 y ss.

Ver nota 13.

Como un ejemplo de ello en la doctrina chilena basta revisar los manuales nacionales, incluso los de nueva factura. Así puede apreciarse en: Benavente Gorroño, Darío, Derecho procesal civil, op. cit., págs. 32 y ss.; y, Rodríguez Papic, Ignacio, Procedimiento civil, Editorial Jurídica de Chile, Santiago, 2003 , págs. 91 y ss.

204 Revista Ius et Praxis - año $14-n^{\circ} 1$

El sistema de recursos procesales en el ámbito civil en un Estado democrático deliberativo

Las razones de la despreocupación por los problemas de prueba, tanto de los teóricos del Derecho como de los procesalistas, podrían situarse en el marco de una específica concepción de la prueba que, siguiendo al profesor italiano Taruffo $^{21}$, puede denominarse como "cerrada". Esta concepción se caracteriza por:

a) Considerar que todo el fenómeno de la prueba está comprendido y recluido en las normas jurídicas que se ocupan del mismo, de forma que sólo vale la pena examinar y sistematizar esas normas

b) Sostener que sólo son pruebas las que están previstas y reguladas en las normas jurídicas específicas, excluyendo la admisibilidad de las denominadas pruebas atípicas

c) Asumir la tendencia a considerar que la regulación jurídica de la prueba constituye un contexto autosuficiente y autónomo respecto de cualquier otro sector o teoría de la prueba en general, no especialmente jurídica.

Si bien, no participamos de la idea de que se pueda hablar de una teoría general de la prueba, en los mismos términos, de una teoría general del proceso ${ }^{11}$. Con todo, podemos aceptar que, en términos generales, no existe ninguna diferencia entre la prueba jurídica y aquella que es propia de cualquier otro ámbito de la experiencia. ${ }^{23}$

Por otro lado, es lógico que en cada uno de los sistemas jurídico procesales civiles y, en su interior, en cada una de los 
órdenes jurisdicciones, puedan regir reglas sobre prueba distintas (regulaciones diversas sobre la admisión, práctica y valoración de la misma). Pero ello no supone necesariamente que la noción de prueba o del hecho probado quede sustancialmente alterada o deba ser construida para cada uno de esos ámbitos.

En cuanto a la expresión prueba, normalmente es utilizada en tres sentidos. En primer lugar, para hacer referencia a los medios mediante los que se aportan o se puede aportar elementos de juicio a favor de una determinada conclusión. Se debe percibir que aún en este sentido se

Taruffo, Michele, La prueba de los hechos, Trotta, Madrid, 2002, págs. 343 y ss.

En este sentido, compartimos la posición de la doctrina alemana que niega la posibilidad de una parte general (incluido el capítulo sobre la prueba) entre el Derecho procesal civil y el Derecho procesal penal. Sobre el tema ver por todos: Grunsky, Wolfgang, Grundlagen des Verfahrensrechts, Gieseking Verlag, Bielefeld, 1974 , págs. 7 y ss.; y, Volk, Klaus, Grundkurs StPO, C.H. Beck, München, págs. 2 y ss.

Para un sector importante de la doctrina, no existe una diferencia conceptual entre prueba civil y penal. Una manifestación de ello son los trabajos realizados por los académicos angloamericanos, para quienes no cabe duda que la prueba (Evidence) tiene una "parte general" común. En este sentido confrontar, entre otros: Anderson, Terence; Schum, David; y, Twining, William, Analysis of Evidence, Cambridge, New York, 2005; y, Twining, William, Rethinking Evidence, Cambridge, New York, 2006.

Revista Ius et Praxis - año $14-n^{\circ} 1205$

Raúl Núñez Ojeda

produce una ulterior ambigüedad. Efectivamente, en ocasiones se hace referencia a los medios de prueba en sentido genérico, para significar los tipos de medios utilizables o aceptados en Derecho (prueba documental, testifical, etc.). En otras ocasiones se hace referencia al medio específico (ej. prueba documental constituida por la escritura pública).

En el segundo de los sentidos, se usa el término prueba para indicar dos actividades consistentes en la aportación de elementos de juicio a favor de una determinada conclusión o la fase del proceso jurisdiccional en el que se realiza esa actividad. Así hablamos de prueba judicial, la fase de prueba, el período de prueba.

Finalmente, el tercer sentido hace referencia al resultado producido por la aportación de elementos de juicio con relación a la confirmación o falsación de una determinada hipótesis acerca de los hechos. En ocasiones se sostiene que este tipo de pruebas tiene un carácter subjetivo, en la medida en que se equipara la prueba "al convencimiento o grado de convicción que produce en la mente del juez"24. Con todo, no debe olvidarse una distinción básica, la que puede y debe trazarse entre que una proposición esté probada y que esa misma proposición sea tenida por probada por algún sujeto ${ }^{25}$.

Para nosotros, baj o el enunciado "está probado que/»" se usa para hacer referencia al resultado de la actividad probatoria desarrollada a favor y/o en contra de la conclusión/». Por tanto, decir que algo está probado equivale a predicar la verdad de aquello que se considera probado. De este modo, no habría diferencias entre las nociones de prueba y verdad ${ }^{26}$. Es decir, una proposición esta probada si los medios de prueba aportados permiten demostrar su verdad ${ }^{27}$.

En la doctrina nacional, esta tesis no goza del beneplácito de los académicos, para quienes la prueba no reconoce como finalidad la búsqueda de la verdad ${ }^{28}$. Aquí se confunde dos

En este sentido: Carocca Pérez, Alex, Manual de Derecho Procesal (Tomo II), LexisNexis, Santiago, 2003, págs. 151 y ss.

Con todo, debe destacarse que también aquí se produce una ulterior ambigüedad. Puede referirse al resultado probatorio de un medio específico de prueba. Otras veces como resultado de la actividad probatoria (todos lo medios de prueba).

Taruffo, Michele, Sui Confini. Scritti sulla Giustizia Civile, II Mulino, Bologna, 2002, págs. 277 y ss. Un panorama completo sobre las teorías de la verdad en la filosofía contemporánea se puede consultar, entre otos: Nicolás, Juan Antonio y Frapollí, María José (Editores), Teorías de la verdad en el sigloXXléenos, Madrid, 1997, y, Valdés Villanueva, Luis M., En búsqueda del significado. Lecturas sobre filosofía del lenguaje, Tecnos, Madrid, 1995.

Confrontar entre otros: Benavente Gorroño, Darío, Derecho procesal civil, op. cit, págs. 32 y ss. (incluso omite pronunciarse sobre el fin de la prueba); Casarino Viterbo, Mario, Manual de Derecho Procesal. Derecho Pro-

206 Revista Ius et Praxis - año $14-n^{\circ} 1$

El sistema de recursos procesales en el ámbito civil en un Estado democrático deliberativo

cuestiones; la primera, es que teleológicamente la finalidad de la institución jurídica de la prueba es la averiguación de la verdad sobre determinados hechos a los efectos de aplicarles, como consecuencia jurídica, determinadas soluciones normativas. La segunda cuestión concierne a si la verdad es o no un elemento definitorio de la prueba, en el sentido expresado anteriormente, de modo que no pueda considerarse de ningún modo que una proposición está probada si es falsa. 
La prueba debe ser considerada como medio a través del cual el Derecho pretende determinar la verdad de las proposiciones en el marco del proceso judicial. Por otro lado, dadas las limitaciones de ese medio, la presencia del mismo no garantiza la obtención del fin (la verdad).

Las distintas limitaciones procesal (normas contra-epistemológicas) y no procesales (tiempo, costo y medios humanos) que pueden interferir en la determinación de la verdad de los enunciados declarativos de hechos probados, produce que en algunas ocasiones se declaren probados enunciados falsos. ${ }^{29}$

Frente a ello se presentan dos alternativas, o bien se abandona la definición de la prueba en términos de verdad, esto es, la relación conceptual entre ambas nociones, o bien se sostiene que en los casos en que se declara probado un enunciado acerca de los hechos que resulta falso, en realidad no está probado.

La doctrina alemana de finales del siglo XIX salvó este problema inventando una distinción entre dos tipos de verdades, a saber: la verdad formal o forense y la verdad material o real. ${ }^{30}$

La verdad material, es aquella de la que se habla fuera del proceso jurisdiccional. Por ello, también puede hacerse referencia a la misma mediante la denominación de verdad en sentido fuerte. Esta verdad sería en la mayor parte de los casos inalcanzable en el proceso judicial. Por otro lado, tenemos la verdad formal (o verdad en sentido débil), que es aquella que se obtiene en el proceso como resultado de la actividad probatoria. Dicha verdad formal puede coincidir con la verdad material, pero sería aquella la que gozaría de autoridad jurídica. ${ }^{31}$

cesal Civil (Tomo III), Editorial Jurídica de Chile, Santiago, 1997; Carocca Pérez, Alex, Manual de Derecho

Procesal (Tomo II), op. cit, págs. 151 y ss.; etc. También en Argentina es la regla general, como lo muestra:

Arazi, Roland, La prueba en el proceso civil, La Roca, Buenos Aires, 1998, págs. 31 y ss.

En el mismo sentido, pero con referencias al proceso penal ver por todos: Hassemer, Winfried, Einführung in die

Grundlagen des Strafrecht, CH. Beck, München, 1990, págs. 147 y ss.

Fairén Guillen, Víctor, Doctrina general del Derecho Procesal, JM. Bosch, Barcelona, 1992, passim.

Büllow, Oskar, Zivilprozessrecht (Reedición del original 1895), Mohr, Tubingen, 2004, págs. 203 y ss.

Revista Ius et Praxis - año 14 - n 1207

Raúl Núñez Ojeda

En la primera mitad del siglo XX se alzaron importantes voces de la doctrina para rechazar explícita y claramente la distinción entre diversos tipos de verdad. En este sentido cabe mencionar la contribución del procesalista italiano Carnelutti32: "la verdad es sólo una y la verdad formal y material no tiene asidero alguno en la ciencia moderna". En otras palabras del mismo autor, "la verdad es como el agua, es pura o no es verdad". Por tanto para esta parte de la dogmática la solución es que debe abandonarse la relación conceptual entre prueba y verdad.

Así las cosas, entre el procesalismo tradicional se identifican tres grandes tesis ${ }^{33}$ :

a) La prueba como fijación de los hechos. Se sostiene que la finalidad de la prueba es la fijación de los hechos por parte del juez con independencia de su relación con lo ocurrido. Críticas: 1) No hay una diferencia sustancial entre esta tesis y la de la verdad formal; 2) En ambos casos se produce una confusión entre atribución de efectos jurídicos, de autoridad a una decisión judicial y su corrección, incluso jurídica.

b) La prueba como convicción del juez acerca de los hechos. La prueba es el conjunto de operaciones por medio de las cuales se trata de obtener el convencimiento del juez respecto de unos datos determinados. Críticas: 1) Como en el caso anterior, se confunde el carácter jurídico de una resolución con su infalibilidad; 2) La noción de hecho probado (esto es, la prueba como resultado probatorio) es considerada de forma equivalente con la formación de la convicción. Así en este caso también hay escaso margen para el error, ya que si el juez alcanza la convicción el hecho está probado (problema de los recursos) 
c) La prueba como certeza del juez acerca de los hechos. La actividad procesal que tiende a alcanzar la certeza en el juzgador respecto de los datos aportados por las partes. Críticas: 1) no está claro cuáles son los límites entre la noción de convicción y la de certeza en este contexto (parece que la noción de certeza tiene el carácter de subjetivo)

Finamente, para nosotros, el punto de partida para resolver el problema entre prueba y verdad de una proposición es la distinción entre "ser verdadera" y "ser tenida por verdadera". Una proposición $p$ es verdadera si, y sólo si se da el caso que $p$. Ésta es la clásica noción de verdad que se utiliza es la de "verdad como correspondencia" defendida entre otros por Tarski ${ }^{34}$. Es decir, si se produce una correspondencia entre aquello que dice el enunciado y los

Carnelutti, Francesco, La prueba civil, Depalma, Buenos Aires, 1982, pág. 222. Montero Aroca, Juan, La prueba en el proceso civil, Tecnos, Madrid, 2005, págs. 42 y ss. Tarski, Alfred, Logic, Semantics, Metamathematics, Hackett, Indianapolis, 1983, págs. 152 y ss.

208 Revista Ius et Praxis - año $14-n^{\circ} 1$

El sistema de recursos procesales en el ámbito civil en un Estado democrático deliberativo

hechos del mundo. Por tanto, la verdad de la proposición/» que se menciona en el enunciado probatorio (está probado que $p$ ) no depende en absoluto de lo que decida el juez, al emitir el enunciado probatorio en su decisión ${ }^{35}$. Tampoco depende de nada que haya podido suceder en el transcurso del proceso, ni de los medios de prueba aportados al mismo, etc. Depende única y exclusivamente, de su correspondencia con el mundo: de que los hechos que $p$ describe se hayan producido efectivamente. ${ }^{36}$

Lo que sí depende del juez que decide el caso es considerar a $p$ como verdadera. Esto es, el juez puede tener a $p$ por verdadera en su decisión, a la luz de los elementos de juicio aportados al expediente judicial para probar la verdad de la proposición, e incorporarla como razonamiento decisorio, o no tenerla por verdadera ${ }^{37}$. Vale la pena señalar que la decisión de no tenerse por verdadera la proposición/» no se debe confundir con la decisión de tenerla por falsa. Ésta es otra diferencia entre el valor de la verdad de $p$ y el hecho de que sea tenida por verdadera por alguien. En el primer caso, sólo dos opciones son posibles: la proposición es verdadera o falsa. En el segundo, en cambio, existe una tercera opción o posibilidad intermedia: puede considerarse ap como verdadera, como falsa (no-/?) o no atribuirle valor de verdad. En este último caso es cuando no se dispone de elementos de juicio suficientes a favor ni en contra de la proposición/».

¿Cuál es la relación de lo antes señalado con la prueba jurídica? El problema puede verse de la siguiente manera: la finalidad de la prueba como institución jurídica es la de permitir alcanzar el conocimiento acerca de la verdad de los enunciados fácticos del caso ${ }^{38}$. Cuando los específicos medios de prueba incorporados en el proceso aportan elementos de juicio suficientes a favor de la verdad de una proposición, entonces puede considerarse que la proposición está probada. En ese caso, el juez debe incorporarla a su razonamiento decisorio y tenerla por verdadera.

En el mismo sentido: Dalbigant-Deharo, Gaélle, Venté scientifique et vérité judicictire en droitprivé, L.G.D.I,
París, 2004, págs. 195 y ss.
Para una revisión de las teorías de la verdad desde el prisma del Derecho, consultar por todos: Neumann, Ulfried,

Wahrheit im Recht. Zu Problematik und Legitimitát einer fragwürdigen Denkform, Nomos Verlag, Baden-Baden,

2004, págs. 11 y ss. Finalmente, para un análisis desde el ámbito del proceso penal confrontar por todos: Stamp,

Frauke, Die Wahrheit im Strafrerfahren, Nomos Verlag, Baden-Baden, 1998, págs. 13 y ss.

Taruffo, Michele (con Comoglio Luigi Paolo y Ferri, Conrrado), Lezioni sul proceso civile, T. I, II Mulino,

2006, págs. 413 y ss.

Aquí seguimos la opinión de Ferrer Beltrán: Ferrer Beltrán, Jordi, Prueba y verdad en el derecho, Marcial

Pons, Madrid, 2002, pág. 84.

Revista Ius et Praxis - año $14-n^{\circ} 1209$

Raúl Núñez Ojeda 
En todo caso, podría añadirse que, a posteriori de la decisión judicial, una vez que la sentencia halla pasado en autoridad de cosa juzgada y salvo excepciones, a los efectos jurídicos lo que le importará será aquello que el juez ha tenido por verdadero y perderá relevancia aquello que es verdadero (en el supuesto que difieran). Pero éste esun problema únicamente de atribución de efectos jurídicos que no tiene nada que ver con la verdad de ninguna proposición.

Recapitulando, los jueces al decidir un caso realizan un discurso de aplicación o adecuación sobre la base de fijar, a través de los medios de prueba, la verdad o falsedad de las afirmaciones sobre los hechos vertidos por la partes durante el juicio jurisdiccional. Así las cosas, una vez fijados los supuestos de hecho que determinan la aplicación de una norma legal y legitima por sobre otra debe realizar una actividad de justificación que permita comprobar, frente a sus pares y frente a la sociedad en general, la corrección de su decisión.

\section{4.- La 0 ral i dad y la inmediación frente al discurso de aplicación o adecuación}

Todo legislador al estructurar un sistema procesal debe elegir entre dos modelos contrapuestos de estructuración del procedimiento civil, son en realidad dos criterios de organización de la tutela procesal ${ }^{39}$. Efectivamente, el legislador de turno debe elegir entre un procedimiento oral o uno escrito ${ }^{40}$. Más allá de los argumentos esgrimidos a favor de uno o de otro, se podría decir que existe una clara tendencia a nivel mundial a favor de la oralidad, como

\footnotetext{
Aquí seguimos la nomenclatura utilizada por Ramos Méndez en: Ramos Méndez, Francisco, El sistema procesal español, JM. Bosch, Barcelona, 1992, págs. 377 y ss. Sobre los principios del proceso civil en el sentido tradicional ver, entre otros ver: Cortés Domínguez, Valentín, "La Constitución española y los principios rectores del proceso civil", Principios Constitucionales en el proceso civil. Cuadernos de derecho judicial, CGPJ, Madrid, 1993, págs. 139 y ss., y, Vázquez Sotelo, José Luis, "Los principios del proceso civil". Justicia, 1993, págs. 599 y ss.
}

Desde finales del siglo XIX en Alemania se apostó por la oralidad en el ámbito del proceso civil. Prueba de ello son los manuales de la época que apuestan decididamente por la oralidad (Vg. Schonke, Adolf, Derecho Procesal Civil, Bosch, Barcelona, 1950, págs. 42 y ss.). En Chile el Profesor Tavolari Oliveros señala "(...) cuando se detiene la marcha a la búsqueda de un mejor régimen de comunicación procesal, y se repara en la finalidad del esfuerzo, surge un amplio espectro de submetas valiosas, dignas de consideración, todas las cuales se orientan al fin último de una mejor justicia: así, la celeridad; la inmediación, en cuanto facilidad de formar la convicción del juzgador; la concentración; la dirección cabal del proceso por el juez, etc., constituyen todos valores menores que, no obstante, deben preservarse en la ordenación procedimental. Así las cosas, las posibilidades concretas de opción, en el establecimiento de los sistemas comunicacionales al interior del proceso no terminan siendo numerosas: o nos comunicamos oralmente, o lo hacemos por escrito, o buscamos una fórmula intermedia que importe la expresión oral y un registro posterior escrito (..)" (Tavolari Oliveros, Raúl, "La oralidad en el proceso civil de América Latina", El proceso en acción, Libromar, Valparaíso, 2000, pág. 313).

210 Revista Ius et Praxis - año $14-\mathrm{n}^{\circ} 1$

El sistema de recursos procesales en el ámbito civil en un Estado democrático deliberativo

criterio de organización de la tutela procesal ${ }^{41}$, y con ella hacia la concentración e inmediación de actuaciones ante los tribunales de justicia como su necesaria consecuencia.

Por tanto, una vez establecida la oralidad como el criterio de organización de la tutela procesal cabe preguntase si ello tiene alguna repercusión frente a la actividad desarrollada por el juez en el procedimiento de adjudicación.

Si la labor realizada por los jueces al resolver un caso es precisamente un discurso de aplicación o de adecuación y no de legitimación, discurso que solo le corresponde al Legislador, cobra una importancia inusitada la fijación de los hechos que rodean al caso para determinar cual, de la varias normas jurídicas legal y legítima prima facie aplicables, es la mas adecuada al caso concreto que se conoce. Por tanto, frente a la falta de actas que dejen constancia de cada actuación desarrollada por las partes dentro del enjuiciamiento civil respectivo y mor del sistema de libre apreciación de la prueba ${ }^{* 1}$ como método de apreciación de la misma, queda claro que al único tribunal que le corresponde fijar como verdaderas o falsas las afirmaciones sobre los hechos formuladas por las partes es al juez de instancia.

Una vez establecido lo anterior, el diseño institucional del sistema de recursos en contra de la resolución dictada por el tribunal de instancia requiere del cambio del paradigma ${ }^{43}$ tradicional en esta materia ${ }^{44}$. Efectivamente en el derecho histórico, el grado de apelación representó, en líneas generales, una garantía procesal de Derecho común, beneficiosa para los justiciables,

Como se muestra en el trabajos de derecho comparado dirigidos por Zuckerman, Trocker y Varano: Zucker-man, Adrian A. (Editor), Civil Justice in Crisis. Comparative Perspectives of Civil Procedure, Oxford University Press, Oxford, 1999, passim.; y, Trocker, Nicoló y Varano, Vincenzo, The Reforms of Civil Procedure in Comparative Perspective, Giappichelli Editore, Torino, 2005, passim. Sobre las bondades de la oralidad en el proceso de reforma del Derecho Procesal Civil italiano ver: Denti, Vittorio, "La oralidad en la reforma de proceso civil", Estudios de Derecho probatorio, EJEA, Buenos Aires, 1974, pags. 241 y ss.; y, Consolo, Claudio, Le tutele, Cedam, Padova, 


\author{
2003, págs. 3 y ss. \\ Sobre el tema de la libre apreciación de la prueba es obligado consultar: Walter, Gerhard, Freie Beweiswürdi-gung, Mohr, Tubingen, 1978, passim.
}

Con esta terminología se alude a la funcionalidad que cabe asignarle al concepto de paradigma luego de la tesis de Kuhn (Kuhn, Thomas, Estructura de las Revoluciones Científicas, Fondo de Cultura Económica, Ciudad de México, 1971, passim), trasladando este termino al ámbito legal o de la dogmática jurídica. Sobre el sistema de recursos en un procedimiento civil moderno consultar, entre otros: Gilles, Peter, Rechtsmit-tel im Zivilprozess, Athenaum, Frankfurt, 1972, págs. 200 y ss. También consultar: Rosenberg, Leo; Schwab, Karl Heinz; y Gottwald, Peter, Zivilprozessrecht, CH. Beck, München, 2004, págs. 929 y ss; y, Grunsky, Wolfgang, Zivilprozessrecht, Luchterhand, Berlin, 2003, págs. 186 y ss. Por España ver: Ramos Méndez, Francisco, Guía para una transición ordenada a la LEC, JM. Bosch, Barcelona, 2000, págs. 477 y ss.; y Gtmeno Sendra, Vicente, Derecho procesal civil, Colex, Madrid, 2004, págs. 551 y ss.

Revista Ius et Praxis - año 14 - $n^{\circ} 1211$

Raúl Núñez Ojeda

pues permitía extraer el proceso de ambientes enrarecidos por las pasiones localistas, al tiempo que sanear los ánimos.

Sin embargo, la propia existencia de la doble instancia ha sido una materia cuestionada por la doctrina tradicional ${ }^{45}$. Básicamente, se cuestiona su viabilidad desde una doble perspectiva:

- $\quad$ En primer lugar, si el enjuiciamiento de un mismo asunto por dos órganos diferentes ofrece una mayor garantía de seguridad y acierto que la labor de uno solo, se dice que la garantía aumentaría en caso de ser un número superior a dos instancias que puedan llegar a conocer del litigio.

- En segundo lugar, si nos atenemos a los criterios de experiencia del personal jurisdiccional, relacionado con la complejidad jurídica de los asuntos que se someten al primer grado de jurisdicción, se cuestiona el por qué no encomendar desde el principio, la decisión del proceso a esos órganos colegiados más expertos y mejor preparados.

Por tanto, debemos reconocer que el recurso de apelación debe dejar de ser el medio de impugnación ordinario en contra de la sentencia definitiva de primera instancia dictada en un juicio civil. Pero de inmediato surge una serie de preguntas: ¿Qué remplazará al recurso de apelación? ¿Bastará con dejar el sólo recurso de Casación para el control de las sentencias dictadas por los tribunales de instancia? ¿Los tribunales superiores podrán alterar la apreciación de los hechos realizada por el tribunal de instancia?

\title{
5.- El recurso de nulidad civil
}

Las interrogantes planteadas son las mismas que discutió el Foro de la reforma procesal civil y después la comisión redactora del anteproyecto ${ }^{46}$. Efectivamente, al reducir el ámbito de operatividad del recurso de apelación y dejar como único recurso en contra de la sentencia definitiva de instancia el recurso de casación, se corría el peligro de que el excesivo rigor formalista que acompaña al instituto de la casación redujera el ámbito de la revisión de la sentencias a una mera declaración retórica de aquellas que los Legisladores del mundo usualmente realizan.

Entre otros consultar: Solé Riera, Jaume, El recurso de apelación, JM. Bosch, Barcelona, 1998, passim; García Rostan Calvín, Gema, El recurso de apelación en el proceso civil, Colex, Madrid, 2001, passim; y, Oromí i Vall-Llovera, Susana, El recurso de apelación en el proceso civil, Atelier, Barcelona, 2002, passim. Confrontar con: Núñez Ojeda, Raúl, "Hacia un nuevo proceso civil en Chile. Un estudio sobre el movimiento de reforma de la justicia civil al sur del mundo", Revista Actualidad Jurídica, op. cit, págs. 33 y ss.

212 Revista Ius et Praxis - año $14-n^{\circ} 1$

El sistema de recursos procesales en el ámbito civil en un Estado democrático deliberativo

Por tanto, la solución debería venir por establecer, en contra de la sentencia definitiva del juez de instancia, un recurso extraordinario pero sujeto a un bajo nivel de formalidades ${ }^{47}$. Así las cosas, se miró con buenos ojos la experiencia que la reforma procesal penal había generado en esta materia al introducir en nuestra legislación el nuevo recurso de nulidad. ${ }^{48}$

Con el establecimiento del recurso de nulidad civil se busca salvar el gran escollo dogmático que hubiera significado mantener un recurso de apelación incompatible con el nuevo diseño institucional de procedimientos orales y sujetos al sistema probatorio de libre apreciación de la prueba, como con la propia actividad desarrollada por los juez al resolver un caso, que como señalamos al comienzo no es otro que un discurso de aplicación o adecuación. Al mismo tiempo, el reemplazo del tradicional recurso de casación por el de nulidad permite, por una parte, liberarse de la tradición excesivamente formalista que siempre ha acompañado al instituto, como también por otra, escapar de la propia autocomprensión que nuestra Corte Suprema tiene de la Casación, que por decir lo menos, bordea lo racionalmente aceptable. $^{49}$

En cuanto al problema de que es lo que se puede controlar vía recurso de nulidad, vale la pena hacer algunas precisiones 
previas en torno a los sistemas de valoración de la prueba.

Practicadas las pruebas, el juez debe formar un juicio sobre el material probatorio aportado por las partes ${ }^{50}$. La actividad anterior es necesaria ya que hasta ahora las partes han realizado el trabajo de solicitar y rendir la prueba.

A toda esta actividad se la denomina "valoración de la prueba". Y consiste, más propiamente, en la verificación de los enunciados fácticos introducidos en el proceso a través de los medios de prueba, así como el reconocimiento a los mismos de un determinado valor o peso en la convicción del juzgador sobre los hechos que se juzgan. Teniendo en cuenta que la

\begin{abstract}
En el mismo sentido me expresé en el comentario del libro de los profesores M.I. Horvitz y J. López "Derecho Procesal Penal Chileno": Núñez Ojeda, Raúl, "Comentario al Libro Derecho Procesal Penal chileno de Horvitz y López", Revista Actualidad Jurídica, número 17, Universidad del Desarrollo, Santiago, 2008, págs. 592 y ss.

Monográficamente sobre el tema en Chile consultar por todos: Cortez Matcovich, Gonzalo, El recurso de nulidad. Doctrina y jurisprudencia, LexisNexis, Santiago, 2006, passim. También se puede consultar, pero menos interesante desde el aspecto dogmático, el libro: Rieutord Alvarado, Andrés, El recurso de nulidad en el nuevo proceso penal, Editorial Jurídica de Chile, Santiago, 2007, passim
\end{abstract}

Para un análisis y crítica de la labor de la Corte Suprema como Tribunal de Casación ver: Atria Lemaitre, Fernando, "La Casación como problema", Revista de Derecho, N ${ }^{\circ}$ 2, Universidad Adolfo Ibáñez, Legis, Santiago, 2006, pág. 249 y ss.

Para algunos autores la valoración es sólo una cuestión de criterios sociológicos y psicológicos, entre otros ver: Gorphe, Francois, Apreciación judicial de las pruebas, Temis, Bogotá, 1985, passim.

Revista Ius et Praxis - año 14 - nº 1213

Raúl Núñez Ojeda

fijación judicial de los hechos se produce a través de un procedimiento institucionalizado, es posible configurar dos distintos modelos de valoración. ${ }^{51}$

El modelo de la prueba legal tasada es simple en términos teóricos: la técnica de la prueba legal consiste en la producción de reglas que predeterminan, de forma general o abstracta, el valor que ha de atribuirse a cada tipo de prueba. Por el contrario, el sistema de libre valoración, presupone la ausencia de estas reglas e implica que la eficacia de cada prueba para la determinación del hecho sea establecida caso a caso, siguiendo criterios no predeterminados, discrecionales y flexibles, basados esencialmente en prepuestos de la razón. ${ }^{52}$

Desde un punto de vista histórico, la aparición del sistema de la prueba legal tasada representó un avance respecto del sistema de las "ordalías", en que claramente el juez decidía de manera irracional el conflicto, al no reconocerse la búsqueda de la verdad como fin del procedimiento probatorio ${ }^{53}$. Efectivamente, el sistema legal de prueba permitió dar una imagen de racionalidad al procedimiento de valoración de la prueba, permitiendo, además, el control del mismo por el superior jerárquico. ${ }^{54}$

En este mismo sentido, se debe entender que con el paso del tiempo el sistema de la prueba legal fue cayendo en el descrédito. Efectivamente, el rechazo de la prueba legal y la adquisición del principio de la libre convicción tiene sentido, desde el punto de vista epistemológico, sólo si se asume que la prueba judicial de los hechos no proporciona resultados irrefutablemente verdaderos, sino sólo probables. Es entonces cuando debe desacatarse, por inconsecuente con el presupuesto epistemológico del que se parte, cualquier valoración predeterminada de los medios de prueba. Por tanto, el sistema de libre valoración de la prueba lo que hace es proscribir que, con el fin de buscar la verdad sobre los hechos de la causa, deba darse por probado lo que, ha juicio del juzgador, todavía no goza de un grado de probabilidad aceptable. ${ }^{55}$

Gascón Abellán, Mariana, Los hechos en elDerecho, Marcial Pons, Madrid, 1999, pág. 157. Ver entre otros: Nobili, Massimo, IIprincipio del libero convencimento del giudice, Giuffre, Milano, 1974, passim; Walter, Gerhard, Freie Beweiswürdigung, op. cit, passim; y, Tournier, Clara, L 'intime conviction du Juge, PUF, Paris, 2003, passim.

Como lo deja de manifiesto: Foucault, Michele, La verdad y las formas jurídicas, Gedisa, Barcelona, 1995, passim.

Cappeletti, Mauro, El proceso civil en el Derecho comparado, Ara Editores, Lima, 2006, págs. 96 y ss.; y, Taruffo, Michele, La prueba de los hechos, op. cit., págs. 387 y ss. Walter, Gerhard, Freie Beweiswürdigung, op. cit., págs. 75 y ss.

214 Revista Ius et Praxis - año 14 - nº 1

El sistema de recursos procesales en el ámbito civil en un Estado democrático deliberativo

Sin embargo, aunque éste fuera su sentido originario en la ilustración, no es así como ha sido concebido por amplios 
sectores de la doctrina y praxis postilustrada, donde la libre valoración pasó pronto a ser entendida como valoración libre, sin sujeción a reglas de ningún tipo. Es decir, el juez llega a la libre convicción de los hechos a través de un sistema intelectivo particular y subjetivo propio de cada individuo. Esta versión extrema del sistema de libre valoración de la prueba podría estar justificada si estuviera basada en una teoría del conocimiento que fuera adecuada para la averiguación de la verdad. Pero es difícil sostener esta conclusión, ya que la concepción epistemológica que subyace a esta doctrina viene a decir que el método más fiable para conocer los hechos consistiría en procurar que el sujeto cognoscente llegue a estar convencido de los mismos sea cual fuere el razonamiento por el que llegue a ese convencimiento. ${ }^{56}$

En un Estado democrático deliberativo ${ }^{57}$, el sistema de valoración de la prueba debe ser el de libre valoración (Freie Beweiswürdigung). En la dogmática alemana contemporánea, se entiende que el sistema de libre valoración de la prueba (o sana crítica) actúa sobre la base de la convicción del juzgador se forma a través del contenido global de los debates (fase de discusión) y el resultado de la eventual recepción de la prueba (fase de prueba) ${ }^{58}$. Así, se entiende que ésta fórmula tiene un doble contenido, por un lado, ella expresa que todo lo que haya sido objeto del debate y de prueba es aprovechable en la sentencia (salvo que nos encontremos ante una prohibición producción de prueba que derive una prohibición de valoración de la misma $\left.{ }^{59}\right)^{60}$. Por tanto, el aspecto positivo de la formula no acarrea problemas de comprensión.

No ocurre lo mismo con el llamado aspecto negativo de la fórmula, que sugiere que el juez, al formase su convicción, solo debería utilizar aquello que fue objeto del debate. Por tanto, no podría aprovechar su "saber privado" (Private Wissen). Esta limitación atiende, según la doctrina contemporánea ${ }^{61}$, a la imposibilidad psicológica de juzgar imparcialmente

González Lagier, Daniel, Quaestio Facti. Ensayos sobre prueba, causalidad y acción, Palestra, Lima, 2005, págs. 77 y ss.

Habermas, Jürgen, Faktizitat und Geltung, op. cit, págs. 349 y ss.

También se puede ver en Italia, aún cuando se refiere al proceso penal: Nobili, Massimo, IIprincipio del libero convincimento delgiudice, op. cit, págs. 384.

Sobre el tema de prohibición de producción de prueba y prohibición de valoración en el campo penal, consultar: Dallmeyer, Jeans, Beweisführug im Strengbeweisverfahren, BOD, Frankfurt, 2002, págs. 33 y ss.; y, Jager, Christian, Beweisverwertung und Beweisverwertungsverbote um Strafprozess, CH. Beck, München, 2002, passim.

Walter, Gerhard, Freie Beweiswürdigung, op. cit., págs. 262 y ss. Walter, Gerhard, Freie Beweiswürdigung, op. cit., págs. 270 y ss.

Revista Ius et Praxis - año $14-\mathrm{n}^{\circ} 1215$

Raúl Núñez Ojeda

(objetiva) $^{62}$ cuando uno mismo es testigo. Con todo, como sabemos existe una excepción a la regla anteriormente señalada. Es decir, existen algunos casos en los cuales el saber privado del juez puede ser aprovechado, a saber: el notorium factum $^{63}$. Para definir un hecho notorio debemos recurrir a la doctrina europea central. Para Tournier ${ }^{64}$, el fundamento de la excepción se encuentra en la economía procesal y se puede definir como notorio lo que el juez sabe o pude comprobar sin la menor dificultad, sea cual fuere su fuente, al menos fuera del proceso concreto.

Por otro lado, uno de los límites más importantes que tiene el juez al fijar su convicción de acuerdo al debate y prueba rendida (mas allá de del tema antes mencionado de los hechos notorios) es el deber que pesa sobre el mismo de fundamentar su decisión. Efectivamente, frente a la pregunta de si es posible controlar el razonamiento que sigue un juez en un sistema de libre valoración de la prueba (o sana crítica), la respuesta no puede ser sino positiva. He ahí la importancia del deber de fundamentar las sentencias, ya que vía recurso de Nulidad, se puede revisar la determinación de los hechos que realizó el juez de instancia

En el sistema de prueba legal tasada es muy fácil establecer cuándo el tribunal de Nulidad puede entrar a valorar los hechos fijados por el juez de instancia, ya que solo es necesario que éste no respete las normas reguladoras de la prueba. Las que no son otras que aquellas que el legislador ha establecido al regular el valor probatorio de cada uno de los medios de prueba.

Pero en un sistema de libre valoración de la prueba (o sana crítica) al parecer podría ser mas difícil que en el supuesto anterior. En realidad se trata de una mayor complejidad aparente. Efectivamente, el control en este caso se ejerce a través del razonamiento del juez. En la doctrina se distinguen tres caminos para obtener el control sobre la convicción del juzgador, a saber: el llamado argumento de consecuencia, que se basa en el principio lógico de la no-contradicción y persigue que la decisión judicial no sea contradictoria, es decir que el tribunal sea consecuente en su razonamiento práctico; el llamado argumento de totalidad, en virtud del cual las pruebas deben explicar la totalidad de circunstancias sobre hechos que 


\begin{abstract}
Sobre el tema de la imparcialidad objetiva consultar: Núñez Ojeda, Raúl, "La imparcialidad objetiva del juzgador penal y el principio acusatorio (el caso español)", Revista de Derecho y Jurisprudencia y Gaceta de los Tribunales, número 1, Santiago de Chile, 1998, págs. 1 y ss.
\end{abstract}

En la doctrina comparada la excepción es aceptada por todos, ver entre otros: Stein, Friedrich, El conocimiento privado del juez, CEURA, Madrid, 1990, págs. 133 y ss.; y, Walter, Gerhard, Freie Beweiswürdigung, op. cit, págs. 271 y ss. Tournier, Clara, L'intime conviction du Juge, op. cit., págs. 247 y ss.

216 Revista Ius et Praxis - año $14-n^{\circ} 1$

El sistema de recursos procesales en el ámbito civil en un Estado democrático deliberativo

tienen importancia para la decisión; y, el argumento de coherencia ${ }^{65}$, que consiste en un test de probabilidad cuando no se dispone de una prueba directa mediante la observación inmediata, en este sentido, casi todas las disputas jurídicas se refieren ha hechos ya acontecidos, y como ningún hecho del pasado es susceptible de prueba directa, la coherencia narrativa es un test de importancia en la justificación de las decisiones ${ }^{66}$. En definitiva, la vulneración de las normas de las máximas de experiencia y de las reglas de la lógica importa la vulneración de una ley.

La observancia de las leyes del razonamiento no constituye un límite de la apreciación de la prueba, sino que es inmanente a ésta. En otras palabras, cuando se trata de la observancia de las leyes del razonamiento, no hay lugar para una apreciación, como tampoco lo hay en la observancia de las leyes de la naturaleza. Existe solo una apreciación correcta, que es la que la ley natural o la que el razonamiento ha establecido ${ }^{67}$. Solo hay libertad de apreciación allí donde hay algo que puede ser de un modo diverso, o sea, cuando hay una alternativa. Si las leyes de la herencia genética nos dicen que es imposible que la persona $X$ sea el padre de la criatura $Y$, no cabe apreciación de la prueba.

Por otro lado, siempre será posible interponer un recurso de Nulidad alegando la vulneración del artículo 328 del anteproyecto de Código de Procesal Civil cuando se omite algunos de los requisitos que de acuerdo al legislador debe tener una sentencia judicial, en especial, las consideraciones de hecho o de derecho que sirven de fundamento a la sentencia (art. 366 c) ACPC).

Un tema no menos importante, es el que si nosotros somos fieles a la función epistemológica que realiza el juez durante un procedimiento de adjudicación, debería mantenerse el mecanismo del reenvío para la mayor parte de los casos y dejando el sistema de sentencia de reemplazo para el supuesto de vicios incurridos en la sentencia (arts. 378 y 380 ACPC). Con todo, desde un punto de vista psicológico el mecanismo de la sentencia de reemplazo es un incentivo perverso para los jueces de los tribunales de nulidad, especialmente de aquellos encargados de alcanzar la uniformidad en la interpretación de la ley. Efectivamente, la fuerte atracción que ejerce sobre ellos la idea de hacer justicia materia al caso concreto les lleva a perder de vista su función y a buscar enraizadas interpretaciones para poder dictar finalmente una sentencia de reemplazo y

MacCormick, Nils, "Coherente in The Legal Justification", Theory of legal Science (Ed. Roermund), Dordrech,

1984, págs. 48 a 55.

Portados ver: Gottwald, Peter, DieRevisioninstanz als Tatsacheninstanz, Dunckerund Humblot, Berlin, 1975,

passim. Sobre la noción de sentencia defectuosa y de impugnación recursiva en Alemania ver: Jauernig, Oth-

mar, Das fehlerhafte Zivilurteil, Klostermann, Frankfurt, 1958, págs. 3 y ss.

Dworking, Ronald, Law's Empire, Hart, London, 1986, págs. 225 y ss.

Revista Ius et Praxis - año $14-n^{\circ} 1217$

Raúl Núñez Ojeda

hacer justicia al caso concreto. Por ello más de algún autor ha propuesto la vuelta a la estructura original de la casación revolucionaria y establecer como único mecanismo el reenvío frente a una sentencia o juicio anulado. ${ }^{68}$

\title{
6.- El recurso de nulidad en el anteproyecto de Código Procesal Civil
}

Finalmente, al momento de abordar la redacción del anteproyecto de nuevo Código Procesal Civil, la comisión se encontró que a pesar de existir un consenso sobre la necesidad de avanzar hacia la supresión del recurso de apelación como medio de impugnación contra las sentencias definitivas ${ }^{69}$, la dudas sobre la composición de los futuros tribunales civiles (colegiados o unipersonales) reavivó el debate. ${ }^{70}$ 
En este escenario se llegó a una solución de consenso. Dejar abierta la puerta de las dos soluciones en conflicto, es decir, la coexistencia del recurso de apelación y el recurso de nulidad en contra de las sentencias definitivas o la eliminación del recurso de apelación en contra de la misma, para que sea el Foro de la reforma quien decida entre los dos modelos.

Así las cosas, el artículo 346 del anteproyecto señala que: "(••) serán apelables todas las sentencias definitivas y las sentencias interlocutorias de primera instancia, siempre que pongan término al juicio o hagan imposible su continuación (..)". Por su parte, el artículo 368 del mismo, dispone que: "(••) el recurso de nulidad tiene lugar, por las causales previstas en la ley, contra sentencias definitivas inapelables y contra sentencias interlocutorias inapelables cuando ponen término al juicio o hacen imposible su continuación, dictadas por Cortes de Apelaciones o por un tribunal arbitral de segunda instancia constituido por arbitros de derecho en los casos en que estos arbitros hayan conocido de negocios de la competencia de dichas Cortes".

En cuanto a las causales del recurso de nulidad, se sigue una técnica similar a la contenida en el Código Procesal Penal del 2000. Efectivamente, se distinguen entre causales genéricas del

Atria Lemaitre, Fernando, "La Casación como problema", Revista de Derecho, op. cit, págs. 254 y ss. Consenso que se plasmó en el documento de la Universidad de Chile denominado "Propuesta de bases para redactar un nuevo Código Procesal Civil para la República de Chile". El texto se puede consultar en: Revista de Derecho Procesal, N 20, Universidad de Chile, Santiago, 2005, págs. 437 y ss.

Para una crítica de la utilidad práctica de la existencia de dos jueces distintos (de instrucción y de juicio oral) en el ámbito civil en el marco del sistema procesal civil italiano consultar el artículo de: Pisan, Andrea Proto, "La eficacia del proceso civil en Italia", Para un proceso civil eficaz, Ramos Méndez, Francisco (Editor), Ediciones Universidad Autónoma de Barcelona, Barcelona, 1982, págs. 203 y ss.

218 Revista Ius et Praxis - año 14 - nº 1

El sistema de recursos procesales en el ámbito civil en un Estado democrático deliberativo

recurso y las específicas. Las genéricas están contenidas en el artículo 365, en el que podemos identificar las de nulidad en la forma en la letra $a$ ) del mismo artículo ${ }^{71}$, y en la letra $b$ ) la nulidad de fondo ${ }^{72}$. Finalmente, el artículo 366 del anteproyecto contiene las llamadas causales específicas del recurso de nulidad, que sigue la técnica del recurso de revisión ${ }^{73}$ (casación alemana) ${ }^{74}$. En realidad, las causales específicas son causales de nulidad en la forma.

\section{7.- El problema de la posible vulneración del derecho al recurso}

Un tema que también rondo en las discusiones de la comisión redactora del anteproyecto fue, precisamente, el de la compatibilidad del cambio de paradigma con la autocomprensión

Artículo 365 del ACPC. Causales genéricas del recurso. Procederá el recurso de nulidad en contra de la sentencia:

a) Cuando en la tramitación del juicio o en el pronunciamiento de la sentencia, se hubieren infringido sustancialmente derechos o garantías asegurados por la Constitución o por los tratados internacionales ratificados por Chile que se encuentren vigentes, $\mathrm{y}$

Artículo 365 del ACPC. Causales genéricas del recurso. Procederá el recurso de nulidad en contra de la sentencia:

b) Cuando en el pronunciamiento de la sentencia, se hubiere hecho una errónea aplicación del derecho que hubiere influido sustancialmente en lo dispositivo del fallo, existiendo sobre la materia de derecho objeto del recurso distintas interpretaciones sostenidas en diversos fallos emanados de los tribunales superiores.

En el ámbito de la revisión penal ver: Sarstedt, Werner y Hamm, Reiner, Die Revision in Strafsachen, De Gruyter, Berlin, 1998 , págs. 136 y ss.

Artículo 366 del ACPC. Causales específicas del recurso. La sentencia será anulada cuando concurra alguna de las siguientes causales: a) Cuando la sentencia hubiere sido pronunciada por un tribunal incompetente, o no integrado por los jueces designados por la ley; cuando hubiere sido pronunciada por un juez o con la concurrencia de un juez legalmente implicado, o cuya recusación estuviere pendiente o hubiere sido declarada por tribunal competente; y cuando hubiere sido acordada por un menor número de votos o pronunciada por menor número de jueces que el requerido por la ley, o con concurrencia de jueces que no hubieren asistido al juicio; b) Cuando la sentencia hubiere sido dictada en oposición a otra sentencia, pasada en autoridad de cosa juzgada, siempre que ésta se haya alegado oportunamente en el juicio; c) Cuando en la sentencia se hubiere omitido alguno de los requisitos relativos a la exposición clara, lógica y completa de cada uno de los hechos y circunstancias que se dieren por probados y de la valoración de los medios de prueba que fundamentaren dichas conclusiones de acuerdo los principios de la lógica, las máximas de la experiencia y los conocimientos científicamente afianzados como las razones legales o doctrinales que sirvieren para calificar jurídicamente cada uno de los hechos y sus circunstancias y para fundar el fallo; d) Cuando la sentencia se hubiere dictado ultrapetita, esto es, otorgando más de lo pedido por las partes, o extendiéndola a puntos no sometidos a la decisión del tribunal, sin perjuicio de la facultad que éste tenga para fallar de oficio en los casos determinados por la ley; e) Cuando la sentencia contenga fundamentos o decisiones contradictorias; f) Cuando la sentencia hubiere sido dada en apelación abandonada o desistida; g) Haberse omitido el emplazamiento del demandado para la contestación de la demanda, la citación de las partes para la audiencia preliminar o la audiencia de juicio en primera instancia; o la fijación de la causa en tabla para su vista por el tribunal de segunda instancia; h) La omisión de diligencias probatorias ofrecidas oportunamente por la indebida declaración de inadmisibilidad, ilegalidad, impertinencia, sobreabundancia o ilicitud de ellas; i) La 
rendición de diligencias probatorias en una forma no prevista en la ley; y, j) El impedimento o entorpecimiento infundado para que la partes participe en la rendición de la prueba.

Revista Ius et Praxis - año 14 - nº 1219

Raúl Núñez Ojeda

que el sistema interamericano tiene de la llamada garantía constitucional del derecho al recurso. ${ }^{75}$

Mas allá de la crítica que se puedan dirigir al movimiento neoconstitucionalista, por la creación del modelo del juez activista y la interpretación desmedida e ilegítima de las garantías constitucionales en los sistemas procesales ${ }^{76}$, es posible responder de manera afirmativa frente a la pregunta sobre la compatibilidad del modelo de supresión de los recursos de apelación y de

Para una visión del llamado derecho al recurso en el proceso panal confrontar por todos: Yáñez Velasco, Ricardo, Derecho al recurso en el proceso penal, Tirant lo Blanch, Valencia, 2001, passim.

Frente al dilema de las llamas garantías constitucionales del proceso, seguimos la opinión sustentada por el profesor Jeremy Waldron. Es decir, frente a una teoría refractaria a una filosofía política liberal, complaciente con el elitismo constitucional y simplista frente a la protección jurisdiccional de Derechos fundamentales, proponemos tomar en serio la idea del autogobierno. Este compromiso nos llevará a defender una concepción mayoritaria de la política, a juzgar negativamente la constitucionalización de una carta de derechos, y a calificar como inadecuado el método del control judicial como hoy lo conocemos en Chile y el mundo como contra-may-oritario. Si la democracia es valiosa no es sino porque reconocemos la igualdad básica de todos los ciudadanos y su capacidad para tomar decisiones autónomas (para desarrollar un plan de vida racional) o deliberar con los demás con los que se encuentra en desacuerdo, acerca de cuál es la mejor solución a un problema común. Por ello se identifica al Parlamento (democrático) como la institución que da forma casi natural ha armonizar estos valores, y como un órgano especialmente bien situado para lidiar con las circunstancias de la política. Esta opinión choca frontalmente con la sustentada por una parte importante de la doctrina que habla de la "tiranía de la mayoría" y que elaboran intrincadas teoría neoconstitucionalistas a través de un férreo control jurisdiccional de la constitucionalidad de las leyes. Para nosotros estas teorías suponen un desconocimiento de la idea del respeto que nos merecemos las personas por parte del Leviatán.

Así las cosas, para nosotros existe una importante conexión entre derechos y la idea de democracia, así como la existencia de ciertos derechos individuales que deben ser considerados para tener una decisión mayoritaria legítima. Para lo anterior se distingue tres clases de derechos individuales: a) Derechos que de hecho son constitutivos del proceso democrático (derecho de participación); b) Derechos que, aunque no sean formalmente constitutivos de la democracia, representan en todo caso condiciones necesarias para su legitimidad (libertad de expresión y asociación); y, c) Derechos totalmente desvinculados de la democracia (derechos de sucesión patrimonial). Al menos los derechos de las dos primeras categorías, aunque por razones diferentes y de modos diversos, son imprescindibles para cualquier modelo democrático de legitimación.

Si partimos del hecho inevitable del desacuerdo, tendremos que admitir también la existencia de desacuerdos importantes acerca del número, contenido o alcance de los derechos. Por tanto nos enfrentamos a un problema de autoridad, es decir, quedamos entregados a la necesidad de encontrar una vía a través de la que resolver nuestras disputas. En este ámbito, el derecho a la participación aparece como una salida especialmente adecuada. Efectivamente, la participación es un derecho cuyo ejercicio parece peculiarmente apropiado en situaciones en la que los portadores razonables de derechos discrepan acerca de qué derechos tienen. Por ello nuestro autor los llama el derecho de los derechos, porque en definitiva, la participación y la decisión mayoritarias se muestran como las únicas herramientas que, en las circunstancias políticas, resultan consistentes con la idea de que todas las personas son fundamentalmente iguales. Sólo ellas parecen hacerse cargo del respeto debido (a toda persona) en tanto que sujeto deliberativo dotado de razón (Waldron, Jeremy, The Dignity of Legislation, OUP, Oxford, 1999, págs.. 7 y ss.; y, Waldron, Jeremy, Law and Disagreement, OUP, Oxfrord, 2001, págs. 23 y ss).

220 Revista Ius et Praxis - año $14-n^{\circ}$

El sistema de recursos procesales en el ámbito civil en un Estado democrático deliberativo

casación, y su reemplazo por un nuevo recurso de nulidad, con la concepción que mantiene la Corte Interamericana de Derechos Humanos del contenido y alcance del Derecho al recurso.

Si bien, toda la discusión a nivel interamericano se ha desarrollado sobre el proceso penal, en atención ha que los pactos sobre Derecho Humanos (suscritos y ratificados por Chile) hacen mención de la garantía del derecho al recurso en el campo de la justicia criminal, es posible que la misma disputa se traslade al ámbito civil, como consecuencia de la interpretación activista del neocostitucionalismo de la garantía constitucional del debido proceso. ${ }^{77}$

Efectivamente, la Corte Interamericana ha mantenido ${ }^{78}$, siempre desde la perspectiva del proceso penal, que el llamado derecho al recurso se satisface con la existencia de una institución procesal que permita que un tribunal superior revise íntegramente el contenido de la decisión del tribunal inferior, negando así, que aquellos recursos que no permiten la revisión de los hechos, superen el estándar que el sistema interamericano dispensa a las personas.

Así las cosas, el recurso de nulidad que se pretende establecer en el nuevo sistema procesal civil cumple con creces el estándar señalado por la Corte. En concreto, permite al tribunal de nulidad entrar a revisar las cuestiones de derecho y de hecho, pero con respeto ha la función que realiza el funcionario público que integra el órgano que ejerce la función de adjudicación en un estado democrático deliberativo, como con el diseño del nuevo enjuiciamiento civil.

\section{8.- Conclusión}

La tesis que defendemos para el nuevo sistema procesal civil chileno es, como se ha señalado en reiteras oportunidades en el trabajo, la del cambio de paradigma del sistema recursivo. 


\begin{abstract}
Para un análisis del debido proceso consultar monográficamente, entre otros: Esparza Leibar, Iñaki, El principio del proceso debido, JM. Bosch, Barcelona, 1995, Vallespin Pérez, David, El modelo constitucional del juicio justo en el ámbito del proceso civil, Atelier, Barcelona, 2002, y, Comolglio, Luigi Paolo, Etica e técnica del "giustoproceso ", Giappichelli, Torino, 2004. Para una visión nacional sobre el mismo ver los trabajos de: Bordalí Salamanca, Andrés, "El debido proceso civil", La constitucionalización de Derecho chileno, Editorial Jurídica de Chile, Santiago, 2003, págs. 251 y ss.; y, Tavolari Oliveros, Raúl, "El proceso civil chileno. Una lectura desde el debido proceso y la eficacia de la Jurisdicción, de cara a la reforma", Tribunales, Jurisdicción y Proceso, Editorial Jurídica de Chile, Santiago, 1994, págs. 44 y ss.
\end{abstract}

Confrontar con el fallo de la Corte Interamerica de Derechos Humanos en la causa "Herrera Ulloa con Costa Rica", CIDH, del 2 de junio de 2004.

Revista Ius et Praxis - año 14 - nº 1221

Raúl Núñez Ojeda

Así, frente al tradicional establecimiento del recurso de apelación, como medio de impugnación de las sentencias definitivas, se propone avanzar hacia el establecimiento de un recurso de nulidad que permita una revisión de los hecho y el derecho, pero de una manera funcional con los cambios que conlleva un proceso civil moderno, oral, concentrado y sometido al sistema de libre apreciación de la prueba. Además, el sistema permitiría ser respetuoso con la función que despliegan los jueces cuando realizan su función jurisdiccional, es decir, el discurso de aplicación o adecuación.

Por último, esta propuesta se encuentra en consonancia, además, con otra tendencia muy marcada en los movimientos de reforma del proceso civil que han operado en los países desarrollados de Europa ${ }^{79}$. La referencia es al movimiento a favor de reconocer mayores poderes al juez civil, poderes que no se agotan en los de dirección del proceso sino que avanzan hacia una nueva figura del juez civil dotado de poderes de producción de prueba de oficio. ${ }^{80}$

Si adoptamos la posición que a través del proceso civil se busca la verdad como correspondencia, en los términos señalados en este trabajo, el reconocimiento de mayores poderes al juez civil es una necesaria consecuencia. Además, ese mayor protagonismo se entrega, precisamente, al juez de instancia o de base, en quien necesariamente debemos $\operatorname{confiar}^{81}$. Por tanto, mayores poderes y confianza son precisamente las palabras claves que todas las recientes reformas propugnan. ${ }^{82}$

Confrontar por todos el reciente estudio de: Van Rhee, Cornelis Hendrik (Editor), European Tradicions in Civil Procedure, Intersentia, Antwerpen, 2005, págs. 269 y ss.

Efectivamente, el proceso es un instrumento sofisticado para la resolución de las controversias entre los particulares, pero al mismo tiempo es un instrumento para la implementación de políticas públicas. En otros términos y desde una perspectiva comunicativa, los tribunales de justicia son aplicadores de los programas legislativos elaborados por el Parlamento, que a su vez, los estructura sobre la base de un programa político que fue votado por una mayoría de los sujetos deliberativos.

Para el Profesor Gottwald (Gottwald, Peter, "Empfehlen sich im Interesse eines effektiven Rechtsschutzes Massnahmen zur Vereinfachung, Vereinheitlichung und Beschrankung der Rechtssbehelfe des Zivilverfarensrec hts? ",Verhandlung des 61, Deutschen Juristentage, Vol. 1, págs. Al y ss.) las reformas procesales deben tender a fortalecer el procedimiento de primera instancia como un elemento fundamental. Así las cosas, la primera instancia se vería altamente favorecida cuando el legislador incorporase un deber procesal general de esclarecimiento, incluso para la parte que no es titular de la carga de la prueba. También en Alemania el Profesor Stürmer (Stürner, Rolf, Die Aufklarungsflich der Parteien des Zivilprozesses, Mohr, Tubingen, 1977, págs. 6 y ss.) ha llegado a sostener que existe un deber general de esclarecimiento procesal que obligaría incluso a la parte que no soporta la carga de la prueba.

En un Dictamen realizado por encargo del Ministerio de Justicia alemán, por los Profesores Prütting y Hom-merich, publicado el 17 de mayo del 2006 , se reconoce el avance que significó para el sistema procesal civil alemán la reforma del año 2002 que aumentó los poderes del juez en materia probatoria (www. bmj. bund. de).

222 Revista Ius et Praxis - año $14-n^{\circ} 1$

El sistema de recursos procesales en el ámbito civil en un Estado democrático deliberativo

Un sistema de impugnación en un Estado democrático deliberativo debe respetar este binomio. Si fortalecemos los poderes del juez de instancia y confiamos en los mismos, necesariamente debemos reducir el nivel impugnación de las sentencias definitivas a niveles racionales. Impugnación que necesariamente pasa por respetar la función jurisdiccional y estructura del nuevo sistema procesal civil.

Revista Ius et Praxis - año 14 - n 1223 